\title{
Developed Method for Treatment of Industrial Wastewater from Edible Oil Industry using Membrane Technology
}

\author{
Sarah Elhady, M. Bassyouni, R. A. Mansour, Medhat H. Elzahar, Mamdouh Y. Saleh
}

\begin{abstract}
Microorganisms and algae growth on surface water are stimulated in surface water in the presence of effluent wastewater from edible oil industries. This leads to depletion of dissolved oxygen (DO) by eutrophication process result in negative impact on aquatic environment. The new regulation in environment agency and increasing market demand are forcing the industrial sectors to consider finding new solutions and sustainable techniques of the wastewater treatment. In this study, reverse osmosis (RO) membrane filtration has been applied to assess the removal performance of emulsified oil from wastewater. Polysorbate 20 (Tween 20) was used as an oil/water emulsifier. Effect of oil concentrations in terms of chemical oxygen demand (COD) and activated carbon unit on removal efficiency and permeate flux have been studied in details. The results elucidated significant improvement in removal efficiency reached to "98\%". The obtained results show promising application of RO membrane (polyamide membrane) at flux "17 L/m2 hr-1". The experiments showed that membrane filtration of wastewater from edible oil is a convenient technique for a possible removal of high concentration of oil (up to $6000 \mathrm{mg} / \mathrm{L}$ ) with "98\%" removal efficiency at permeate flux "17 L/m2 hr-1 "and low fouling rate.
\end{abstract}

Keywords: Edible oil effluent, Reverse osmosis, COD, Removal efficiency.

\section{INTRODUCTION}

The wastewater from edible oil factories mostly produced from the degumming, de-acidification and de-odorization unites [1]. Also blow down of the boiler and washing water that comes from de-oiling of the earth bleaching take part in the effluents in little quantities. Until that time, the

Revised Manuscript Received on February 15, 2020.

* Correspondence Author

Mohamed Bassyouni*, Department of Chemical Engineering, Faculty of Engineering, Port Said University, Port Said, 42526, Egypt \& Materials Science Program, University of Science and Technology, Zewail City of Science and Technology, October Gardens, 6th of October, Giza, 12578, Egypt.

Sarah Elhady, Department of Sanitary and Environmental Engineering. high Institute of Engineering and Technology, New Damietta, Egypt.

R. A. Mansour, Department of Chemical Engineering , Higher Institute of Engineering and Technology, New Damietta, Damietta Egypt

Medhat H. Elzahar, Sanitary and Environmental Engineering, Faculty of Engineering, Port Said, 42526, Egypt \& Department of Civil Engineering, Giza Engineering Institute, Egypt

Mamdouh Y. Saleh, Sanitary and Environmental Engineering, Faculty of Engineering, Port Said, 42526, Egypt \& High Institute of Engineering and Technology, El-Manzala, Ad Daqahliyah, Egypt

(C) The Authors. Published by Blue Eyes Intelligence Engineering and Sciences Publication (BEIESP). This is an open access article under the CC BY-NC-ND license (http://creativecommons.org/licenses/by-nc-nd/4.0/) wastewater discharged direct from edible oil factories into soil and ground water. But, because of the advent of environmental water awareness, the Pollution Control systems have ended up severer and force very tough rules. As well as, Lack of water is other reason for wastewater treatment. For the edible oil wastewater treatment by usual techniques as aerobic or anaerobic breakdown the proportion of BOD to COD would be more than 0.60 [2]. Nevertheless, the wastewater from edible oil factories commonly has its BOD to COD proportion about 0.2 that would lead to damage of micro-organisms beneficial for breaking down. There are many commonly used methods in separation of oil-water treatment. Separation using gravity settling and mechanical techniques are recognized usual methods for treatment, the performance of that based on oil droplets size in effluents. Chemical breaking of emulsion is an active method below suitable usage [3], [4]. Also there were other edible oil separation techniques as air flotation, coagulation [5], [6], and electrocoagulation [7], [8]. On the other hand, these techniques result in massive amount of sludge, difficult procedures, highly energetic and expensive. These drawbacks highlight the necessity for more research using novel separation techniques. Separation using membrane technique has high acceptance through the latest years and becomes an auspicious technique. This technique has numerous benefits as stable permeate characteristic and minor space need. Furthermore no chemical is wanted to be added. Several researches of separation using membrane for treatment edible oil effluents were recorded [9], [10]. Membrane technology showed good performance while used in several wastewater treatment techniques [11], [15]. Reverse osmosis membrane (RO) was used in treatment of varied industrial wastewater [16], [20]. In this paper, the edible oil was separated from effluents by the reverse osmosis (polyamide). Effect of edible oil concentration in feed and effect of pre-treatment on permeate; turbidity and COD rejection efficiency were studied.

\section{EXPERIMENTAL}

\section{A. Materials}

- Synthetic edible oil wastewater was setup by mixing $1 \mathrm{ml}$ of non-ionic surfactant Tween20 to a $5 \mathrm{ml}$ of soybean edible oil and $1 \mathrm{~L}$ of de-ionized water and mixed for "3.5hr" using electric mixer "300 rpm" at mixing. The mixture had a uniform white color. After preparation the emulsion, it was left to observe its stability. 
- Polyamide membrane (PA) in Spiral Wound structure made in USA. Membrane model (TW 30-1812-75), length $26 \mathrm{~cm}$ and diameter $5 \mathrm{~cm}$, maximum operating temperature "45 oC", maximum operating pressure 150psi and the applied pressure "125psi (8.5bar)",permeate flow rate "12 l/h", $\mathrm{pH}$ ranges "2 to 11 " maximum feed flow rate "7.6 l/min", salt rejection "98\%". RO is the important part of module used to remove dissolved solid, all particles, bacteria and organics.

- Granular activated carbon (GAC) filter column dimension" $6.35 \mathrm{~cm} \times 25.4 \mathrm{~cm}$ ". The GAC filter clear away main pollutants in water as total organic carbon (TOC), suspended matter (turbidity), volatile organic chemicals (VOC), chlorine, herbicides, organic solvents, insecticides, pesticides, and chemicals resulting in bad tastes, odors, designed for optimal adsorption. The GAC is capable of delivering up to "3.8 liter per minute" of water.

- High pressure pump (model PKM60), Size"2.54 cm x 2.54 cm", Q.max."40 L/min", H.max. "33m", Suct H" 8m"," .37 kw"," .5HP" and" 2850 rpm".

\section{B. Experimental set-up and operation}

The schematic diagram of oily waste water treatment process using RO unit is shown in "Fig. 1". The membrane was washed and saturated by filtered water before using for fifteen minute to make sure that RO reached to the ultimate force. Mixing tank was filled with synthetic-water emulsion, "40L" of wastewater was charged to the process container. The wastewater charged to the RO unit by using high pressure pump. The filtration was started when the power supply was turned on. The wastewater saved with the same pressure through the process "8.5 bar". The oil concentration in effluents was varied in range "3000 mg/l to $6000 \mathrm{mg} / \mathrm{l}$ ". The treated water comes from RO unit noticed by saving in vessel for "3 min". A total " 5.6 l/hr" of permeate collected in each experiment. The permeate and feed samples were examined for COD, O\&G and turbidity. After the analysis the treat water contains oil concentration more than the discharge limit and the membrane will be afflicted with fouling through usage. Though, many methods to relieve this problem were endeavored, from them the feed pre-treatment. In the feed pretreatment, adsorption GAC

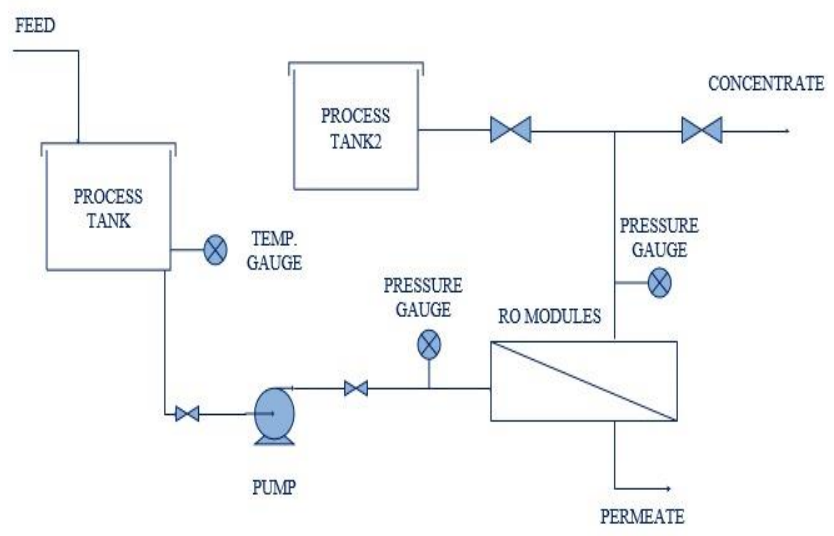

Fig. 1. The diagram shown in picture of edible oil wastewater treatment process using RO system.

Usually applied to clear away organic constituents and remaining disinfectants in treated wastewater. In addition, better taste and color. The pretreatment process is very important for clearing high concentration of edible oil in effluents from edible oil factories that would else strictly block the membrane and cause a shorter membrane life. The pretreatment (GAC); for RO membrane is applied to refine the treated water. A simple flow diagram of the system is shown in "Fig. 2". After treatment using this membrane process, the treated water is proper for irrigation and drainage into the sewage network. The analyses for turbidity, COD for all samples were tested to see the efficiency of each process in the reduction of suspended solid and organic matter.

\section{Measurement and analysis}

The samples of wastewater and treated water were examined for $\mathrm{pH}$, turbidity, O\&G and COD.

\section{- Chemical oxygen demand (COD)}

Chemical oxygen demand for all samples was measured by COD photometer. Suitable amount of sample "0.2 ml" presented into commercially accessible digested solution (HR-Rang: 200-15000mg/l) consisting of potassium dichromate, sulfuric acid and mercuric sulfate. Then blend was heating for "2 hours" at " $150^{\circ} \mathrm{C}$ " in a COD heater (Hatch Company). After oxidation is ended, the COD concentration was examined using a spectrophotometer.

\section{- Turbidity}

The samples of permeate were analyzed for turbidity by using turbidity meter (Lovibond meter with NTU).

\section{- pH (Standard Method)}

The $\mathrm{pH}$ measured by using HANNA instruments pHep $\mathrm{Hi}$ 96107 Pocket-Sized $\mathrm{pH}$ Meter.

\section{- Oil and grease (Hexane Extraction Gravimetric Method)}

$125 \mathrm{ml}$ of sample added to "20ml" ethanol and "20ml" sulfuric, shaking well in separation funnel, add "15 ml" petroleum ether, Stand for "15 min" until two layers was separated, collected the above layer that contains the oil (organic layer), Weight Difference between weight of beaker before and after. Then oil concentration calculated as in "equation (1)"

$$
\text { oil concentration }=\frac{w t(m g)}{\text { volumeofsample }(m l) \times 1000}(1)
$$

\section{Percent rejection and flux modulus}

In Ro membrane unit the separation performance is indicated in terms of \%rejection of COD, turbidity and O\&G or any other feed factors which calculated in" equation(2)"[3]:

$$
R(\%)=\frac{C f-C p}{C f} \times 100
$$

CP is the concentration of permeate solute while CF is its feed solute concentration.

The water flux $\left(\mathrm{J}^{\omega}\right)$ is the volume of permeate while (V) collected per unit membrane surface area (a) per unit time $(\mathrm{t})$ which calculated in "equation (3)":

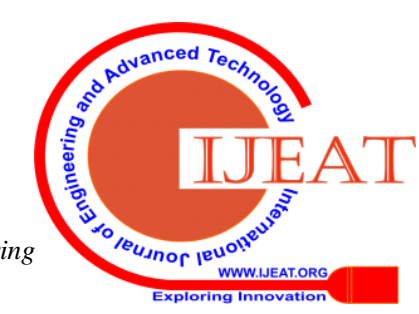




$$
J w=\frac{V}{a x t}
$$

\section{RESULT AND DISCUSSION}

\section{A. Effect of time on permeate flux}

The flux observed to decrease slowly at initial time up to around "3 hr" and after 6hr the flux observed constant at constant (pressure of "8.5 bar" and edible oil concentration in synthetic wastewater" 4080mg/l") as shown in "Fig. 3". That is the usual performance of membrane methods. Water flux affected by the occurrences: concentration polarization and membrane blocking outcome from the continuing rise of the surface layer of extremely accumulated pollutants in membrane pores. This is defining the accumulation of membrane-rejected solutes adjacent to the membrane surface. Concentration polarization rises the permeate pressure at membrane surface, which leads to a decrease in water flux. Blocking is a phenomenon leading to decrease of membrane performance because of accumulating of suspended or dissolved matters on outer layer, at its pore openings and because of the gel layer formation over the membrane surface.

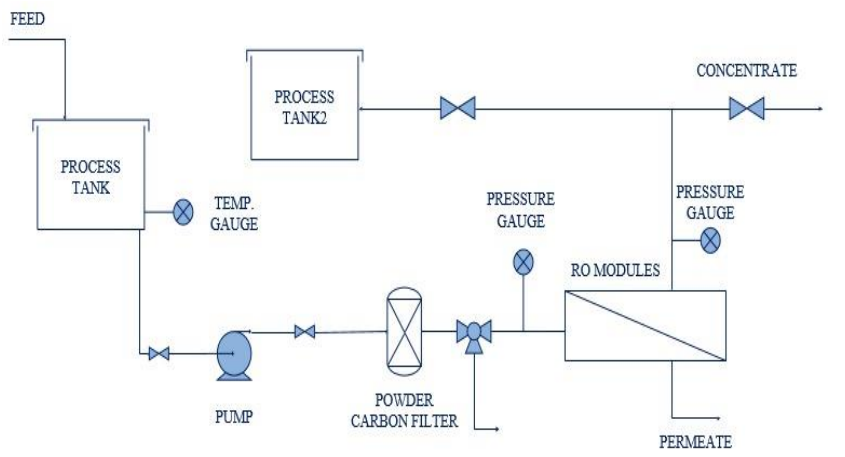

Fig. 2. The diagram shown in picture of edible oil wastewater treatment unit using a pretreatment.

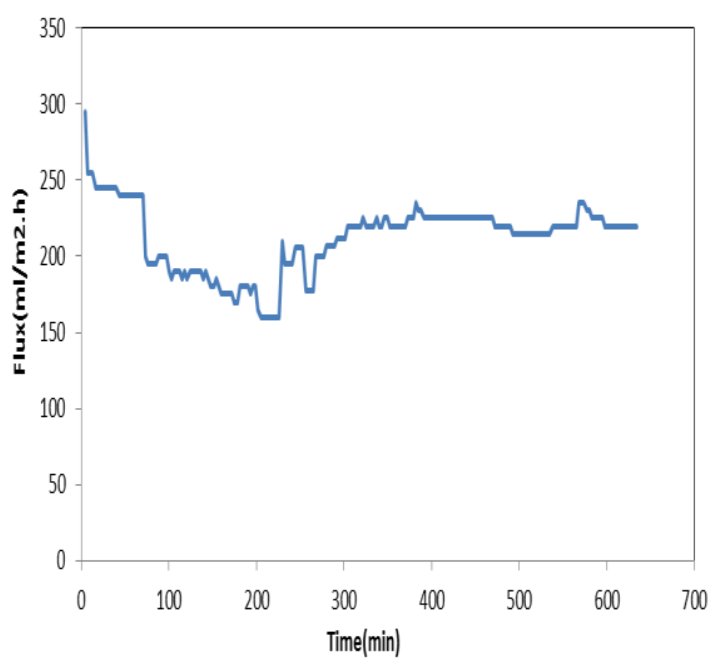

Fig. 3. Effect of time separation on flux.

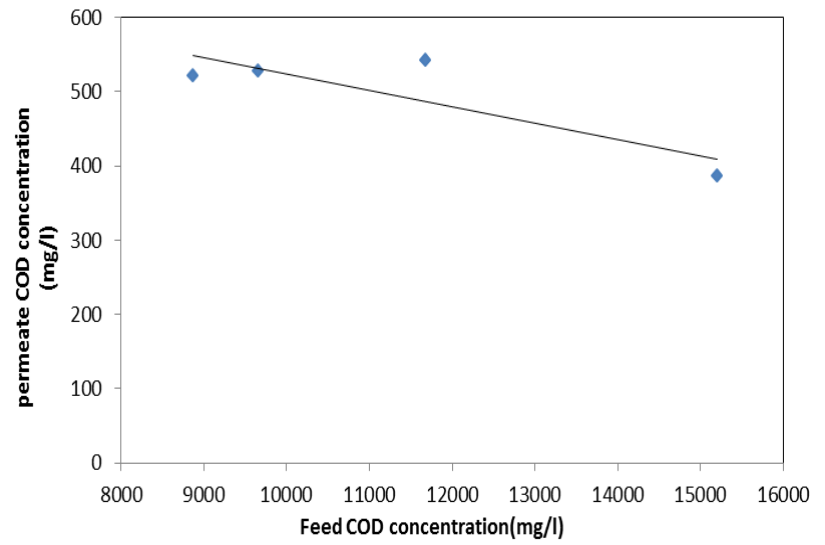

Fig. 4. Effect of feed concentration on permeate COD.

Table- I: Effect of oil concentration in wastewater on treated water properties.

\begin{tabular}{|c|c|c|c|c|c|c|}
\hline $\begin{array}{c}\text { Oil effluent } \\
\text { concentration } \\
(\mathrm{mg} / \mathrm{l})\end{array}$ & $\begin{array}{c}\text { Feed COD } \\
\text { concentration } \\
(\mathrm{mg} / \mathrm{l})\end{array}$ & $\begin{array}{c}\text { Permeate COD } \\
\text { concentration } \\
(\mathrm{mg} / \mathrm{l})\end{array}$ & $\begin{array}{c}\text { Rejection } \\
\text { efficiency \% }\end{array}$ & Feed turbidity(NTU) & $\begin{array}{c}\text { Permeate } \\
\text { turbidity(NTU) }\end{array}$ & $\begin{array}{c}\text { Rejection } \\
\text { efficiency \% }\end{array}$ \\
\hline 5653.33 & 15198 & 386 & 97.46 & 875 & 1.28 & 99.8 \\
\hline 4342.92 & 11676 & 542 & 95.35 & 876 & 1.22 & 99.86 \\
\hline 3298.48 & 8868 & 521 & 94.12 & 890 & 1.6 & 99.82 \\
\hline
\end{tabular}

\section{B. Effect of oil concentration on membrane performance}

Effect of oil concentration in wastewater on treated water properties was examined; saving the wastewater at the same pressure "8.5 bar" as listed in "Table- I" this as wastewater from varied oil industries contains high range of suspended solids and oil concentration.

It describes the upper limit of suspended solid in terms of turbidity and COD removal. The results are presented in" Fig. 4"and "Fig. 5" which show that the proportionately with permeate flux decreased increasing feed concentration. The cause of increasing the rejection efficiency and reducing the permeate COD with the increase in oil concentration was because of the formation of bigger droplets. Furthermore, oil droplets settled by the membrane forming a secondary layer on the membrane surface which additional decreasing the size of pore of the membrane. So, removal was improved and permeate concentration was decreased [21]. The average removal of suspended solid in term of turbidity is "99.82\%". 
The performance of membrane was good COD remained below the permissible levels "<1100ppm" as per Law No. 93 of 1962 for the discharge of wastewater on sewage networks and amended by Ministerial Decree No. 44/20000 but the permeate flux still contains oil and grease concentration "201.6 ppm" more than the permissible 100ppm so the pretreatment is very important.

\section{Effect of pretreatment unit on membrane filtration performance}

Membrane fouling results in decrease in the permeate flux values and concentration polarization which produce resistance formation on the membrane surface throughout filtration. After activated carbon pretreatment the load on membrane decrease and the permeate flux increase "3 times" from "5.6 l/hr to $17 \mathrm{l} / 8 \mathrm{hr}$ ". As listed in "Table- II" and shown in "Fig. 6". After pretreatment the oil rejection increase to "99.89\%" and oil concentration in permeate are all not more than "100 mg/l" which meet the National Discharge Standard of wastewater.

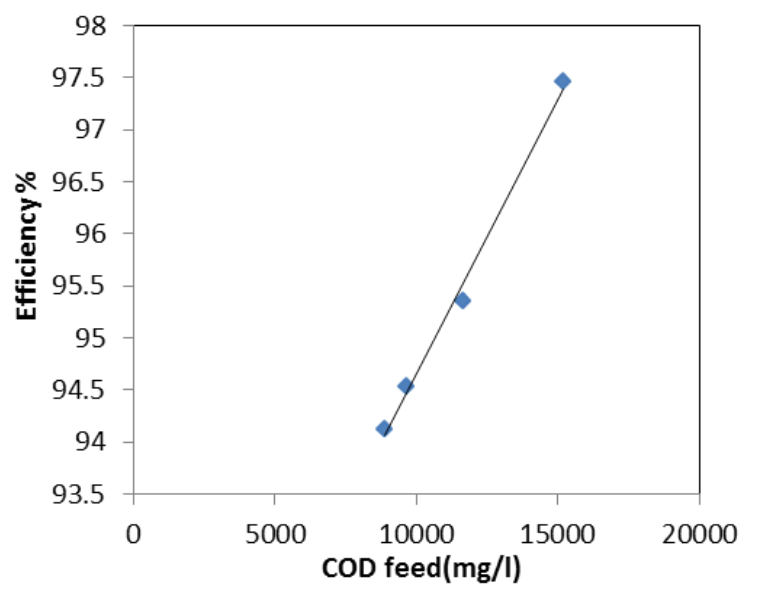

Fig. 5. Effect of feed concentration on COD rejection.

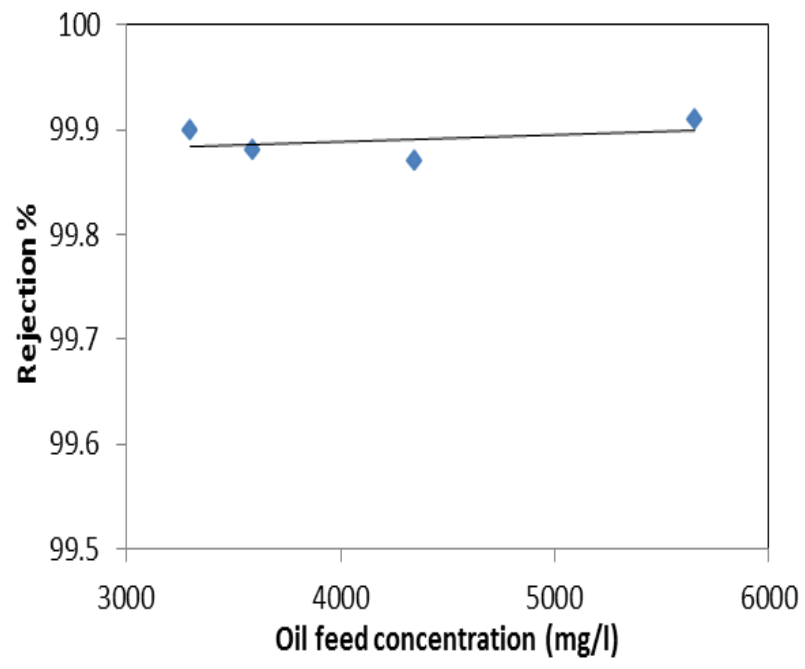

Fig. 6. Effect of pretreatment on oil rejection.
Table- II: Effect of pretreatment on permeate characteristics.

\begin{tabular}{|c|c|c|c|}
\hline $\begin{array}{c}\text { Oil conc of } \\
\text { feed(mg/l) }\end{array}$ & $\begin{array}{c}\text { Oil conc of } \\
\text { permeate before } \\
\text { pretreatment } \\
\text { (mg/l) }\end{array}$ & $\begin{array}{c}\text { Oil conc of } \\
\text { permeate after } \\
\text { pretreatment(m } \\
\text { g/l) }\end{array}$ & Rejection\% \\
\hline 5653.33 & 104.78 & 4.8 & 99.91 \\
\hline 4342.92 & 218.9 & 5.3 & 99.87 \\
\hline 3590.83 & 185.5 & 4.3 & 99.88 \\
\hline 3298.48 & 235.4 & 3.2 & 99.90 \\
\hline
\end{tabular}

\section{CONCLUSION}

Reverse osmosis polyamide membrane achieved a good result in separation oil produced from edible oil factories in their wastewater. On the other hand, large amount of treated water permeated from RO unit with high removal of turbidity, COD and color without using any heaters in this process. The treated water permeated from RO unit is not acceptable because, it still containing oil concentration more than "100mg/l" and not permissible. So the pretreatment using activated carbon filter before RO membrane to decrease the oil concentration in permeated water and the impurities percentage was permissible under Egyptian programme for anti-pollution specific for industrial wastewater.

\section{REFERENCES}

1. V. Kale, S.S.P. Katikaneni, M. Cheryan, Deacidification of ricebran oil by solvent extraction and membrane technology, JAOCS 76 (6) (1999) 723.

2. E.S.K. Chian, F.B. Dewalle, Treatment of high strength acidicwaste water with completely mixed anaerobic filter, WaterRes. 11 (1977) 295.

3. Y.C. Song, I.S. Kim, S.C. Koh, Demulsification of oily wastewater througha synergistic effect of ozone and salt, Water Sci. Technol. 38 (4-5) (1998)247-253.

4. Y.C. Song, I.S. Kim, S.C. Koh, Demulsification of oily wastewater througha synergistic effect of ozone and salt, Water Sci. Technol. 38 (4-5) (1998)247-253.

5. S. Deng, G. Yu, Z. Jiang, R. Zhang, Y.P. Ting, Destabilization of oil dropletsin produced water from ASP flooding, Colloid Surf. A: Physicochem. Eng.Aspects 252 (2-3) (2005) 113-119.

6. A.I. Zouboulis, A. Avranas, Treatment of oil-in-water emulsions by coag-ulation and dissolved-air flotation, Colloid Surf. A: Physicochem. Eng.Aspects 172 (1-3) (2000) 153-161.

7. G. Chen, Electrochemical technologies in wastewater treatment, Sep. Purif.Technol. 38 (2004) 11-41.

8. X. Chen, G. Chen, P.L. Yue, Separation of pollution from restaurant wastew-ater by eletrocoagulation, Sep. Purif. Technol. 19 (2000) 65-76.

9. S. Lee, Y. Aurelle, H. Roques, Concentrationpolarization,membrane foul-ing and cleaning in ultrafiltration of soluble oil, J.Membr. Sci. 19 (1984)23-38.

10. J. Cho, G. Amy, J. Pellegrino, Membrane filtration of natural organic matter:factors and mechanisms affecting removal efficiency and flux decline withcharged ultrafiltration (UF) membrane, J. Membr. Sci. 164 (2000) 89-110.

11. R.D. Noble, S.A. Stern, Membrane Separations Technology: Principles and Applications, Elsevier, Amsterdam, 1995.

12. Elhenawy, Y., Nabil AS Elminshawy, M. Bassyouni, Adnan Alhathal Alanezi, and E. Drioli. "Experimental and theoretical investigation of a new air gap membrane distillation module with a corrugated feed channel." Journal of Membrane Science 594 (2020): 117461. 
13. Bassyouni, M., M. H. Abdel-Aziz, M. Sh Zoromba, S. M. S. Abdel-Hamid, and Enrico Drioli. "A review of polymeric nanocomposite membranes for water purification." Journal of Industrial and Engineering Chemistry, 73, 25 Pages 19-46 (2019).

14. Elrasheedy, Asmaa, Norhan Nady, Mohamed Bassyouni, and Ahmed El-Shazly. "Metal organic framework based polymer mixed matrix membranes: Review on applications in water purification." Membranes 9, no. 7 (2019): 88.

15. Ali, Imtiaz, Omar A. Bamaga, Lassaad Gzara, M. Bassyouni, M. H. Abdel-Aziz, M. F. Soliman, Enrico Drioli, and Mohammed Albeirutty. "Assessment of blend PVDF membranes, and the effect of polyme concentration and blend composition." Membranes 8, no. 1 (2018): 13

16. Soliman, M. F., M. H. Abdel-Aziz, Omar A. Bamaga, Lassaad Gzara, F. Sharaf, M. Al-Sharif, Z. Bassyouni, and R. Ahmad. "Performance evaluation of blended PVDF membranes for desalination of seawater RO brine using direct contact membrane distillation." Desalination Water Treat 63 (2017): 6-14.

17. 17. Maddah, Hisham A., Abdulazez S. Alzhrani, Ahmed M. Almalki, M. Bassyouni, M. H. Abdel-Aziz, Mohamed Zoromba, and Mo hammed A. Shihon. "Determination of the treatment efficiency of different commercial membrane modules for the treatment of groundwater." J. Mater. Environ. Sci 8, no. 6 (2017)

18. Bassyouni, M., A. E. Mansi, Alaa Elgabry, Basma A. Ibrahim, Omar A. Kassem, and R. Alhebeshy. "Utilization of carbon nanotubes in removal of heavy metals from wastewater: a review of the CNTs' potential and current challenges." Applied Physics A 126, no. 1 (2020): 38.

19. R. Rautenbach, R. Albrecht, Membrane Processes, Wiley,Chichester, 1989.

20. B. Chakrabarty, A.K. Ghoshal, M.K. Purkait, Ultrafiltration of stable oil-in-wateremulsion by polysulfone membrane, J. Membr. Sci. 325 (2008) 427.

\section{AUTHORS PROFILE}

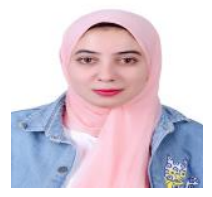

Sarah elhady demonstrator at civil Engineer department, public works, sanitary engineering and currently studying for master at Port Said University, in industrial wastewater treatment which product from edible oil factories using membrane method.

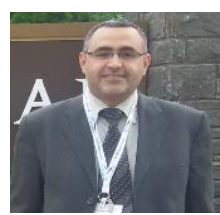

Mohamed Bassyouni is a Professor of Chemical Engineering at Port Said University and Adjunct Professor at Zewail City of Science and Technology. He has completed a postdoctoral at TU-Clausthal, Germany in the area of materials processing. He holds a Ph.D. in Chemical Engineering, Cairo University. He received his master degree in Environmental Engineering from TU-HH, Germany. He obtained his undergraduate degree in Chemical Engineering (1999). He served as the head of Chemical and Materials Engineering Department, the students' Industrial Training Unit and Department-ABET unit at KAU University. $\mathrm{He}$ is a member of the Editorial Board of International Institute of Chemical, Biological and Environmental Engineering and the journal of Engineering-Port Said University. He has experience in the area of polymer composites and applications, with emphasis on nanocomposites, biocomposites, using recyclable materials in favor of environmental sustainability and water treatment. He is the author of more than 70 articles published in international journals and conferences with h. index 15 based on Scopus. He is the co-author of three books in the area of polymers and petroleum engineering. He won the 2014 Dr. Venice Kamel Award (Academic of Scientific Research and Technology) for Scientific Creativity for Young Researchers in the field of materials science and its applications.

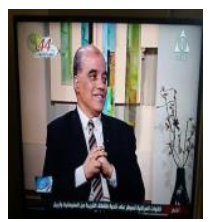

Ramdan Abd- Elghany Mansour, Assistant professor of chemistry, Basic science and engineering department, Higher Institute of Engineering and Technology, New Damietta, Egypt. Director of Quality Assurance Unit. Consultant of wastewater treatment, Specialist of Environmental Impact Assesment.

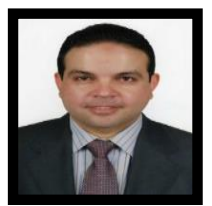

Medhat El-Zahar, Associate Professor specializing in Environmental Engineering with an emphasis on Sanitary and Environmental Hydraulics with more than 15 year's experiencemin teaching at the undergraduate and graduate levels. Extensive experience in the planning, design and implementation of water supply and sanitation networks. He has a Ph. D.in Sanitary and Environmental Hydraulics (2003), Completed via a cooperative research program between Suez Canal University, Egypt, and the Kyushu Institute of Technology, Kitakyushu, Japan. Dissertation: Flotation and Dewatering of Waste Activated Sludge Using Carbon Dioxide. He has M.Sc. in Environmental Hydraulics (1997), Suez Canal University, Port Said, Egypt. Thesis: Improvement of Reliability of Water Distribution Networks. He has B. Sc. In Civil Engineering Department (1992), Suez Canal University, Port Said, Egypt. He is now Adjunct Associate Professor, Head of Department, Giza Higher Institute of Engineering and Technology, Tamooh, Giza, Egypt, 2014-present. Adjunct Assistant Professor, Giza Higher Institute of Engineering and Technology, Tamooh, Giza, Egypt, 2012-2013. Adjunct Assistant Professor, Higher Institute of Engineering and Technology, New Damietta, Egypt, September, 2010-August, 2012, then 2014. Adjunct Assistant Professor, Higher Technological Institute, Tenth of Ramadan, Egypt, 09/2008-Present. Assistant Professor, Port Said University, Egypt, 05/2003-present.

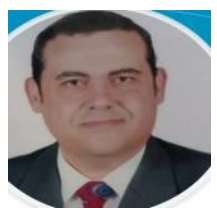

Mamdouh Saleh, Dean of High Institute of Engineering and Technology, El-Manzala, Ad Daqahliyah, Egypt \& Sanitary and Environmental Engineering, Faculty of Engineering, Port Said, 42526, Egypt \& 